\title{
Ghrelin and hypothalamic development: too little and too much of a good thing
}

\author{
Jenny Tong and David D'Alessio \\ Division of Endocrinology, Duke University, Durham, North Carolina, USA.
}

\begin{abstract}
Neural centers in the hypothalamus regulate food intake and body weight in response to hormones and other neural stimuli, and dysfunctional communication between the brain and gut underlies metabolic disorders, including obesity. In this issue of the $J C l$, Steculorum and colleagues present evidence that the gastric peptide ghrelin mediates neural fiber growth in the arcuate nucleus of the hypothalamus during the neonatal period. Neonatal mice subjected to either increased or decreased ghrelin action during this developmental period had an increased risk of obesity in adulthood. Together, the results of this study support a model whereby neural organization at key stages of development sets the foundation for metabolic health later in life.
\end{abstract}

low at P6 and gradually increase to adult levels by P14 in WT mice. The authors then evaluated the effect of short-term interventions in the postnatal period that either decreased or increased ghrelin action. Early administration of ghrelin reduced $\mathrm{ARH}$ fiber development and density in the paraventricular nucleus (PVN), while RNA aptamer-mediated ghrelin blockade increased neural fiber density in this nucleus. In the ARH, both AgRP/NPY- and POMC-producing neuronal cell populations are involved in feeding behaviors. Both of these neuronal cell populations were affected by the increase or decrease in ghrelin action; however, the tendency with both interventions was to shift the innervation of the PVN toward a greater orexigenic tone. One of the more fascinating aspects of these results is that either gain or loss of ghrelin function in the postnatal period led to increased body weight and adiposity in adulthood. These findings strongly suggest that ghrelin signaling in the ARH during development is critical for establishing the regulatory underpinnings of lifelong energy balance.

Leptin, ghrelin, and neurodevelopment

The strengths of the work presented by Steculorum and colleagues (15) are centered on their expertise in evaluating ARH development. Using similar methodology, these investigators previously established a neurodevelopmental role for leptin in the ARH $(16,17)$. A unique aspect of the current approach is the use of an aptamer to antagonize ghrelin action. This particular antighrelin aptamer has been previously shown to effectively block increased food intake and body weight in response to exogenous ghrelin $(18,19)$, and Steculorum and colleagues demonstrated that the compound also inhibits neural activation by ghrelin. The use of aptamers as antagonists in physiologic research is still at an early stage, and several elements of the approach have been questioned. However, both pharmacologic 


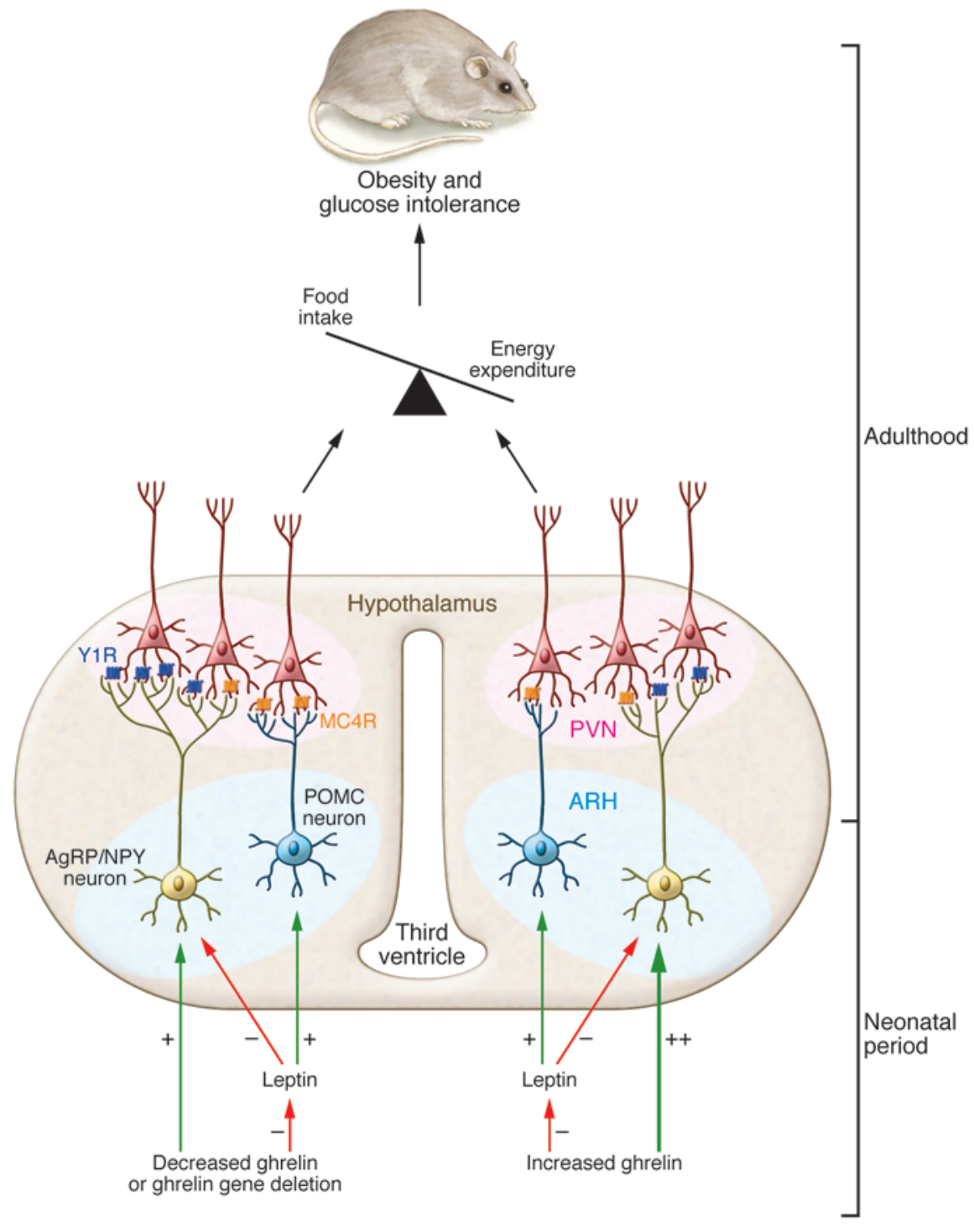

ghrelin antagonism and genetic deletion of ghrelin had similar effects on PVN innervation, providing some internal concordance to support the authors' interpretations (15). In fact, another strength of this study by Steculorum and colleagues is the experimental architecture, which included a logical set of control experiments that allowed the authors to isolate the effects of ghrelin on neural development in the ARH and during the neonatal period. Moreover, evaluation of PVN fiber density as a primary endpoint revealed that increasing and decreasing ghrelin activity during the postnatal period had opposite effects on neuronal projections into the PVN, an outcome with intuitive appeal. Finally, Steculorum and colleagues provide convincing data showing that the effects of ghrelin on ARH fiber density attenuate the effects of leptin (15). A neo- natal surge of leptin is generally thought to be important for normal ARH development $(20,21)$. Therefore, these findings raise the possibility that leptin and ghrelin have inverse actions during neural development, paralleling the well-described anorexicorexigenic counterpoint of their activities as hormones. Taken together, the data from Steculorum et al. (15) suggest that ghrelin activity in the neonatal period influences ARH development by modulating axonal innervation of important secondary sites involved in metabolic control.

The phenotypes of treated mice are critically important for interpretation of the effects of ghrelin on neural fiber density. Inhibition of ghrelin from P4 to P22 resulted in increased food intake, body weight, and adiposity, all of which were notably elevated very soon after aptamer
Figure 1. Alterations in ghrelin levels during the neonatal period promote metabolic dysfunction in adulthood. When ghrelin is antagonized or removed, there is an increase in neuronal projections from the ARH to the $\mathrm{PVN}$, with a predominance of projections from orexigenic AgRP/NPY neurons. Exposure to exogenous ghrelin in the neonatal period results in a reduction of neuronal connections between the $\mathrm{ARH}$ and PVN; however, were there is still a predominance of AgRP/NPY projections. Ghrelin may exert its trophic effect on hypothalamic neurons via leptin and/or through direct interaction with neurons within the $\mathrm{ARH}$. The net effect of altered ghrelin signaling during development is a positive energy balance and glucose intolerance in adulthood.

treatment began (15). While these animals were only slightly heavier than the untreated controls (5\%-10\%) through adulthood, the treated mice exhibited substantial increases in body adiposity as well as glucose intolerance. At first glance, these effects appear subtle; however, their persistence for weeks after only a 14-day intervention is notable. The concordance of phenotypes between aptamer-treated mice and postnatal mice treated with ghrelin for 8 days is remarkable. Ghrelintreated animals also became heavier than did WT animals, albeit at 2 months of age, and fatter and more glucose intolerant as well. The similar outcomes for apparently opposing treatments, one that increased and one that decreased ARH fiber density in the PVN, are seemingly paradoxical. On the basis of the ARH cell types identified by Steculorum and colleagues (see Figure 4, B and C, in ref. 15), it appears that both anti-ghrelin and ghrelin increase the ratio of orexigenic AgRP fibers to anorectic $\alpha$-MSH fibers in the PVN by about $50 \%$. While Steculorum et al. did not formally analyze this parameter, such a shift could contribute to an inherent tendency to overeat throughout life. Certainly, the regulation of food intake is much more complex than one particular pattern of PVN innervation; however, it appears that circuits wired at key points in development have a lasting impact (Figure 1).

\section{Conclusions and future directions}

Beyond the experimental strengths of the study by Steculorum and colleagues (15), the results have considerable physiologic significance and have the potential 
to extend to clinical medicine. For example, bariatric surgery is a common intervention that often reduces circulating ghrelin levels $(22,23)$, and there is only limited information on the long-term metabolic outcomes of children born to mothers who have undergone these procedures. A recent study demonstrated that following vertical sleeve gastrectomy, obese female rats lose weight, exhibit improved metabolic parameters, and have reduced plasma ghrelin (24); however, the offspring of these dams were small at birth, with increased hypothalamic AgRP and decreased POMC expression and a propensity toward obesity and glucose intolerance when fed a high-fat diet (24). Another study found that rats exposed to insufficient nutrition in utero and/or in the postnatal period have elevated circulating ghrelin levels and increased risk of obesity and hyperphagia later in life (25). Together, these studies add support to the notion that increased or reduced ghrelin levels in early life presage metabolic disturbance at a later time. Of note, pregnant women exposed to conditions associated with increased or decreased ghrelin levels, such as over- or undernutrition, put their offspring at risk for developing obesity, diabetes, and cardiovascular disease later in life (26).

Steculorum and coworkers raise one more point of considerable value. The addition of ghrelin to leptin as hormones involved in feeding behavior that also serve as factors controlling hypothalamic development has opened the door for a new conceptualization of the regulation of metabolism by the brain. A growing number of peptides that have cognate receptors on neurons and demonstrated effects on feeding may also have roles in neural development. For example, the proglucagon-derived peptides (GLP1 and glucagon), peptide tyrosine-tyrosine (PYY), and cholecystokinin (CCK) are established satiety factors that could all have alternative, and perhaps primary, actions in shaping the neural foundations of energy homeostasis. Similarly to ghrelin and leptin, these factors could impart distinct developmental and endocrine/neurocrine actions that influ- ence susceptibility to obesity. This possibility presses the need for more studies and a greater understanding of the role of neural development in metabolic control. The results of Steculorum and coworkers raise the possibility that tractable targets exist for intervention at key early stages that have the potential to shape health for the rest of life.

Address correspondence to: David D'Alessio, Duke University Division of Endocrinology, Baker House Room 310, 200 Trent Drive, Durham, North Carolina 27710, USA. Phone: 919.684.5778; E-mail: david.d'alessio @duke.edu.

1. Asakawa A, et al. Ghrelin is an appetitestimulatory signal from stomach with structural resemblance to motilin. Gastroenterology. 2001;120(2):337-345.

2. Tschop M, Smiley DL, Heiman ML. Ghrelin induces adiposity in rodents. Nature. 2000;407(6806):908-913.

3. Kojima M, Hosoda H, Date Y, Nakazato M, Matsuo H, Kangawa K. Ghrelin is a growth-hormone-releasing acylated peptide from stomach. Nature. 1999;402(6762):656-660.

4. Gutierrez JA, et al. Ghrelin octanoylation mediated by an orphan lipid transferase. Proc Natl Acad Sci U S A. 2008;105(17):6320-6325.

5. Yang J, Brown MS, Liang G, Grishin NV, Goldstein JL. Identification of the acyltransferase that octanoylates ghrelin, an appetite-stimulating peptide hormone. Cell. 2008;132(3):387-396.

6. Guan XM, et al. Distribution of mRNA encoding the growth hormone secretagogue receptor in brain and peripheral tissues. Brain Res Mol Brain Res. 1997;48(1):23-29.

7. Zigman JM, Jones JE, Lee CE, Saper CB, Elmquist JK. Expression of ghrelin receptor mRNA in the rat and the mouse brain. JComp Neurol. 2006;494(3):528-548.

8. Williams KW, Elmquist JK. From neuroanatomy to behavior: central integration of peripheral signals regulating feeding behavior. Nat Neurosci. 2012;15(10):1350-1355.

9. Wren AM, et al. Ghrelin causes hyperphagia and obesity in rats. Diabetes. 2001;50(11):2540-2547.

10. Wren AM, et al. Ghrelin enhances appetite and increases food intake in humans. J Clin Endocrinol Metab. 2001;86(12):5992.

11. Sun Y, Ahmed S, Smith RG. Deletion of ghrelin impairs neither growth nor appetite. Mol Cell Biol. 2003;23(22):7973-7981.

12. Wortley KE, et al. Genetic deletion of ghrelin does not decrease food intake but influences metabolic fuel preference. Proc Natl Acad Sci US A. 2004;101(21):8227-8232.

13. Sun Y, Wang P, Zheng H, Smith RG. Ghrelin stimulation of growth hormone release and appetite is mediated through the growth hormone secretagogue receptor. Proc Natl Acad Sci US A. 2004;101(13):4679-4684.

14. Kirchner H, et al. GOAT links dietary lipids with the endocrine control of energy balance. Nat Med. 2009;15(7):741-745.

15. Steculorum SM, et al. Neonatal ghrelin programs development of hypothalamic feeding circuits. JClin Invest. 2015;215(2):846-858.

16. Bouret SG, Draper SJ, Simerly RB. Trophic action of leptin on hypothalamic neurons that regulate feeding. Science. 2004;304(5667):108-110.

17. Bouret SG, Simerly RB. Development of leptin-sensitive circuits. J Neuroendocrinol. 2007;19(8):575-582.

18. Kobelt P, et al. Anti-ghrelin Spiegelmer NOXB11 inhibits neurostimulatory and orexigenic effects of peripheral ghrelin in rats. Gut. 2006;55(6):788-792.

19. Shearman LP, et al. Ghrelin neutralization by a ribonucleic acid-SPM ameliorates obesity in diet-induced obese mice. Endocrinology. 2006;147(3):1517-1526.

20. Ahima RS, Prabakaran D, Flier JS. Postnatal leptin surge and regulation of circadian rhythm of leptin by feeding. Implications for energy homeostasis and neuroendocrine function. J Clin Invest. 1998;101(5):1020-1027.

21. Delahaye F, et al. Maternal perinatal undernutrition drastically reduces postnatal leptin surge and affects the development of arcuate nucleus proopiomelanocortin neurons in neonatal male rat pups. Endocrinology. 2008;149(2):470-475.

22. Cummings DE, et al. Plasma ghrelin levels after diet-induced weight loss or gastric bypass surgery. NEngl J Med. 2002;346(21):1623-1630.

23. Kotidis EV, Koliakos G, Papavramidis TS, Papavramidis ST. The effect of biliopancreatic diversion with pylorus-preserving sleeve gastrectomy and duodenal switch on fasting serum ghrelin, leptin and adiponectin levels: is there a hormonal contribution to the weight-reducing effect of this procedure? Obes Surg. 2006;16(5):554-559.

24. Grayson BE, Schneider KM, Woods SC, Seeley RJ. Improved rodent maternal metabolism but reduced intrauterine growth after vertical sleeve gastrectomy. Sci Transl Med. 2013;5(199):199ra112.

25. Desai M, Gayle D, Babu J, Ross MG. Programmed obesity in intrauterine growthrestricted newborns: modulation by newborn nutrition. Am J Physiol Regul Integr Comp Physiol. 2005;288(1):R91-R96.

26. Sullivan EL, Grove KL. Metabolic imprinting in obesity. Forum Nutr. 2010;63:186-194. 